\title{
Turbulence and Scale Measurements in a Square Channel with Transverse Square Ribs
}

\author{
RICHARD B. RIVIR \\ Wright Laboratory, Aero Propulsion and Power Directorate, Wright-Patterson Air Force Base, Ohio 45433-7251 \\ MINGKING K. CHYU \\ Department of Mechanical Engineering, Carnegie Mellon University, Pittsburgh, Pennsylvania 15213-3890
}

PAUL K. MACIEJEWSKI

Mechanical Engineering Department, University of Pittsburgh, Pittsburgh, Pennsylvania 15261

\begin{abstract}
Hot-wire measurements of the mean flow, turbulence characteristics, and integral scale in a square channel roughened with transverse ribs mounted on two opposing sidewalls are presented for three rib configurations: single rib, in-line multiple ribs, and staggered multiple ribs. Test conditions for multiple ribs use $\mathrm{p} / \mathrm{H}=10, \mathrm{H} / \mathrm{D}=0.17$, and $\mathrm{Re}_{\mathrm{D}}=23,000$. Measured results highlight the spatial distribution and evolution of turbulence intensity and integral scale from the flow entrance of the first period to the developed regime near the exit of the third period. The highly turbulent, shear layer initiated near the trailing upper-edge of a rib elevates the turbulence level in the mainstream of the channel. The magnitude of turbulence intensity in the channel core rises from $0.7 \%$ in the approaching flow to about $20-25 \%$ near the exit of the third period. The integral scale dominating the mainstream flow increases from approximately one-half the rib-height, $0.5 \mathrm{H}$, in the approaching flow to $1.5-2.5 \mathrm{H}$ behind the first rib and further downstream.
\end{abstract}

Key Words: Turbine blade cooling; ribbed channel flows; turbulence; integral scale

\section{INTRODUCTION}

I nternal cooling passages in advanced turbine blades or vanes utilize transverse ribs, arranged in a periodic fashion, to enhance convective heat transfer. Transverse ribs are often termed two-dimensional roughness, in contrast to their three-dimensional counterparts; e.g. sand grain roughness. A surface-mounted rib penetrates the viscous sublayer to promote turbulent transport that increases the heat transfer from the surface. For blade internal cooling, the rib height often amounts to more than $10 \%$ of the passage cross section, and its effect on elevating turbulence levels in the core flow, as well as in the boundary layer, can be significant. Hence ribs are often termed turbulence promoters or turbulators.

Rib-induced heat transfer enhancement exclusively for blade cooling has been a subject of extensive research for more than a decade. Most studies were directed toward investigating the relationship between average heat transfer and friction loss for various channel geometries. Substantially less effort was devoted to examining the local variation of heat transfer over a rib-roughened surface. This local information is deemed to be important, since non-uniform cooling may induce excessive thermal stress and reduce component life-time. Local heat transfer near a transverse rib is determined primarily by the nature of flowfield in the region. Flow past a rib element includes the phenomenon of boundary layer separation, followed by separated shear layer reattachment and boundary layer redevelopment. The distance between the reattachment location and the downstreamfacing wall of the rib is termed the reattachment length, $X_{r}$. In the region of reattachment, the heat transfer coefficient reaches a local maximum - a primary effect of rib-induced enhancement. Hence an effective design of a rib-roughened channel must be able to incorporate the reattachment feature which depends on rib configurations and flow conditions. 
For multiple ribs, the nature of shear layer reattachment, including the value of reattachment length, is primarily determined by the value of pitch-to-height ratio, $\mathrm{p} / \mathrm{H}$. However, reports in this regard to date have been conflicting. According to an earlier study by Mantle [1966], the shear layer reattachment between two neighboring ribs only occurs when $\mathrm{p} / \mathrm{H} \geq 6.6$. Other studies have reported higher values of $\mathrm{p} / \mathrm{H}$, approximately equal to 10 , for the existence of reattachment Aytekin and Berger, [1979]; Han et. al., [1979]; Klein et. al. [1980]. In these studies, the reattachment length, based on actual flow visualization and measurements, varies from $\mathrm{X}_{\mathrm{r}} / \mathrm{H}$ $\approx 3$ to 5 . For studies focused mainly on heat transfer, the reattachment length is treated as the same location of the maximum heat transfer coefficient behind a rib, despite the fact that these two locations may differ by nearly a rib-height Edward and Sheriff, [1962]; Kottke, [1982]. In a more recent study, Chyu and Wu [1989] have reported that a sharp rise of heat transfer coefficient exists immediately ahead of a square rib, with the magnitude of the heat transfer rate generally surpassing that induced by the shear layer reattachment. This finding is consistent with some earlier reports of strong corner vortices and intermittent boundary layer bursts in the region Williams and Watts, [1972]; Simpson, [1981]. The unsteady burst can be a very effective means for heat transfer between the near-wall region and the mainstream. This suggests that optimal $\mathrm{p} / \mathrm{H}$ values, as far as overall heat transfer rate is concerned, may be less than 10 , contrary to the present belief of the blade cooling community.

In light of the foregoing discussion, it appears that there is a need for a study to provide further understanding of flow characteristics in rib-roughened channels. Since turbulent transport is the dominating feature in the system, the present study is focused primarily on examining the spatial distribution and evolution of turbulence from the flow entrance to the developed (periodic) regime. This paper presents hot-wire data to infer the turbulence intensity and integral scale for the first three periods in a square channel. Multiple ribs were mounted on two opposing channel walls, arranged in both in-line and staggered fashions with $\mathrm{p} / \mathrm{H}=10$. All tests used a single Reynolds number of 23,000 , referenced to the channel height, which is within the range of internal blade cooling applications for large turbine engines. In the open literature, there has been much less research focused on the flow aspects than on the heat transfer performance. Several earlier studies have investigated mean velocity and turbulence intensity in channels with multiple ribs Hsieh, [1989]; Yokosawa et. al., [1989]; Sato et. al., [1992]. All these studies were limited to the periodic regime only, and no length scale data were reported.

\section{DESCRIPTION OF EXPERIMENT}

A schematic of the channel and the rib configurations tested is shown in Figure 1. Flow is induced into the test section by a blower located downstream of the channel. The test section made of Plexiglas is $152.4 \times 152.4 \times$ $1524 \mathrm{~mm}$. The cross section of each rib is $25.4 \mathrm{~mm}$ square. This establishes a rib pitch-to-height ratio (p/e) of 10 for both in-line and staggered configurations. The ratio between rib height and channel hydraulic diameter is approximately equal to 6 . Honey comb cells with a cell dimension of $3.2 \mathrm{~mm}$ and a 20 to 1 length-to-diameter ratio are installed at the channel entrance to provide uniform low turbulence flow at the channel entrance. The turbulence level for all first rib locations is nominally less than $0.7 \%$.

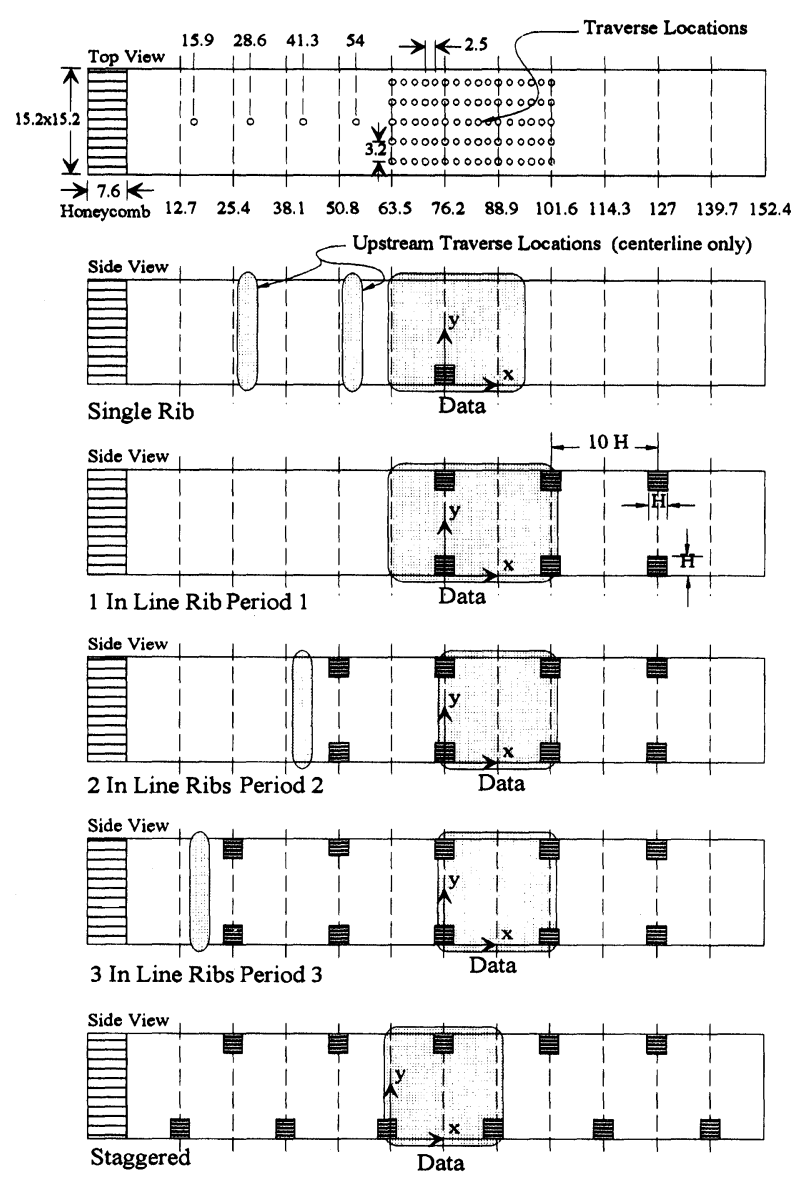

FIGURE 1 Schematic of Test Configurations 
The traverse locations are located in an array of 5 by 16 ports. These ports provide access for hot wire traverse centered in the third period of an in-line array. The top wall ribs of the in line and staggered arrays occupy 1 or 2 rows of the 16 rows. The shaded area of data shown in Figure 1 indicates the traverse locations employed for each of the rib configurations. Centerline traverses were taken to document the flow up stream of the first rib of each configuration as indicated in Figure 1. This arrangement was chosen based on a notion that the transport phenomena with transverse ribs generally reach a periodic state in the third period Berger et. al., [1979]; Chyu and $\mathrm{Wu}$, [1989]. In order to explore the development of the flow for multiple ribs, but without excessive fabrication costs, upstream ribs were removed as shown in Figure 1. The traverses were then repeated at the original third period location. Although the approaching boundary layer thickness is expected to be different for the first, second, and third period cases, this is considered to be a minor factor in developing the scales or fluctuation levels because of the large disturbances produced by the ribs.

The hot wire measurements were made with a TSI IFA 100 anemometer and a TSI $1210 \mathrm{~T} 1.5$ hot wire probe. Bridge mean and rms voltages were measured with two separate HP 3497A voltmeters. 100 readings of the DC and rms voltages were taken by a HP 3452 Scanner using the HPIB interface, converted to velocities averaged and stored by a 386 computer. The mean and rms voltages were read alternately and then averaged. The rms measurements are true rms. Hot wire determinations of velocity are to within $1 \%$ of the reported value for mean velocities across the experimental measurement range. To evaluate its capability for high-fluctuation measurement, the present system has also been checked against laser velocimetry in the wake from a TSI calibrator jet. Up to $20 \%$ turbulence level, the discrepancy between the two instruments is found to be less than $2 \%$ for both mean and rms velocities. However, one should recognize that the turbulence in the wake behind a rib, based upon the actual local velocity in stead of the centerline velocity, can be much higher than the $20 \%$ range.

Single-wire probes are known to be unable to discern streamline reversal and inclination. As a result, the velocity profile points shown in the separation zone only give an absolute value of velocity. Absolute hot wire velocities in the separation or recirculation zone have been compared against Kiel probe measurements and found to agree when the Kiel probe is rotated in the direction of the mean flow. A point of inflection in the velocity profile occurs as a result of the flow reversal. The separation zones are clear from the discontinuity in the mean, fluctuating, and scale profiles, and like wise reattachment has clearly occurred when the discontinuity disappears. The fluctuating component of the vertical velocity has also been measured on the duct centerline with a TSI 1241 crossed hot wire probe and found to equal or exceed the u' component for these flows.

Single element hot wire measurements were employed to obtain the turbulence scales in both axial and vertical directions. Data acquired by the hot wire were introduced to an HP 3562 dynamic signal analyzer which inverted the frequency spectrum with a Fast Fourier Transform (FFT) to provide the autocorrelation function. The autocorrelation function was then normalized by the rms value of the local velocity, integrated over time, and multiplied by the local mean velocity to estimate the longitudinal integral scale. Sixty spectrums, each of 1024 points, were averaged to obtain the autocorrelation function.

\section{RESULTS AND DISCUSSION}

Results presented in this section include mean velocity, turbulence intensity, and integral length scale for multiple ribs in both in-line and staggered configurations. $\mathrm{X}$ and $y$ are measured from the center of the first rib in the period to be studied as indicated for each configuration in Figure 1. A-value for $\mathrm{x}$ indicates a location upstream of the front face of the rib and + value indicates a location downstream of the rear face of the rib. As a baseline case, single rib results are to be discussed first. Although measurements across the channel width were often made to verify spanwise variations, presented are centerline data for all cases.

\section{Single Rib}

Figure 2 shows the mean velocity profile behind a single rib. Measurements with a single element hot wire neither resolve actual flow direction in the separation or recirculation zone nor do they discriminate between an axial or vertical component of velocity in the region behind the rib. The reattachment point, where the near-wall mean velocity gradient is equal to zero, is located approximately at $\mathrm{X}_{\mathrm{r}} / \mathrm{H}=6 \sim 7$. This finding agrees with those from several previous studies. Lamb and Thompson [1983] reported that the reattachment length behind a single rib is $6.85 \mathrm{H}$ and $7.05 \mathrm{H}$ for $\mathrm{Re}=45,000$ and 97,600 , respectively. They used a rib-to-hydraulic-diameter ratio $\mathrm{H} / \mathrm{D}=0.12$ in a $3: 2$ rectangular channel, as compared to the present $\mathrm{H} / \mathrm{D}=0.17$ in a square duct. 

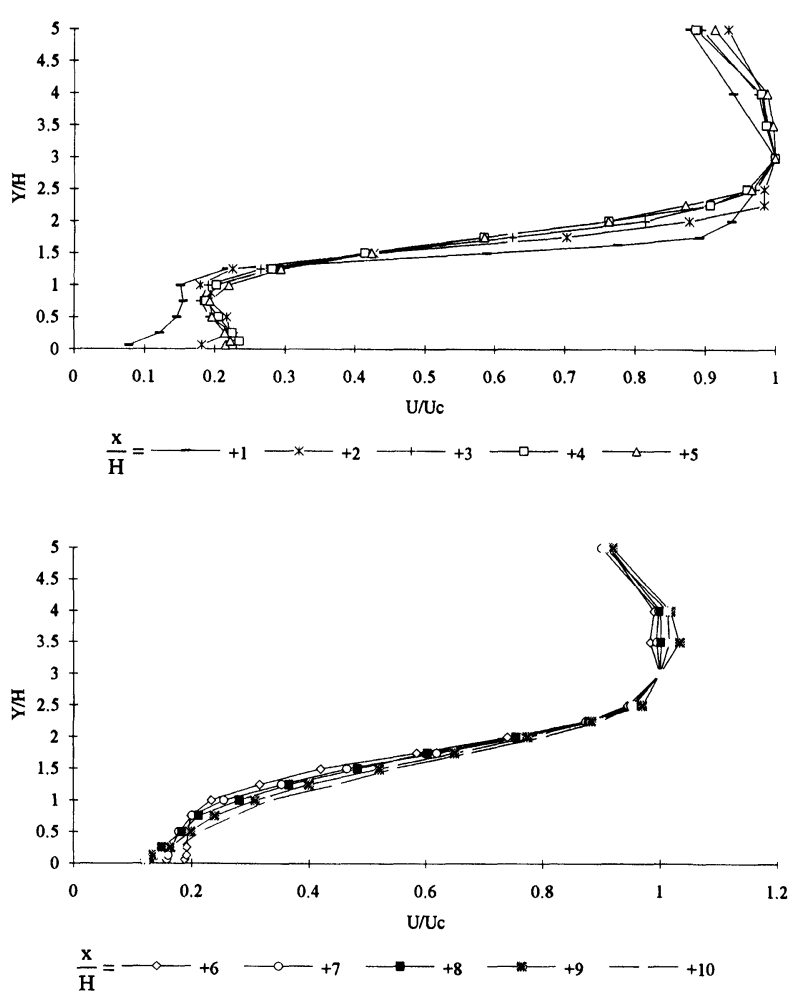

FIGURE 2 Single Rib Mean Velocity

Recently Acharya et al. [1993a and 1993b] found the reattachment point to be $\mathrm{X}_{\mathrm{r}} / \mathrm{H}=5.4$ from their computations and 6.3 from their experiment for a single rib. The Reynolds number used in their study is approximately $25 \%$ lower than the present value, and $\mathrm{H} / \mathrm{D}=0.104$.

Figure 3, a three-dimensional plot, shows the distribution of turbulence intensity, $T u=u^{\prime} / U_{c}$, behind a single rib. Very high turbulence, with peaks around $20 \%$, prevail in the separated shear layer that initiates near the downstream upper-edge of the rib and expands further downstream. One may discern the boundary of the shear layer, the so-called dividing streamline, by tracing the "ridge" of these Tu peaks. The dividing streamline touches the floor near $x / H=7$. This location agrees with the reattachment point determined earlier based on the mean velocity gradient. Underneath the shear layer is the recirculation zone that has relatively lower $\mathrm{Tu}$, about $10 \%$. Above the shear layer, the value of Tu falls to $0.7 \%$ by mid channel.

Also revealed in Figure 3, the magnitude of Tu rises sharply just ahead of the rib, approximately at $\mathrm{x} / \mathrm{H}=-2$ (one and a half rib heights ahead of the front edge of the rib). While this phenomenon existing in a separation zone is somewhat unexpected, it occurs consistently upstream to the first rib even for the multiple-rib cases.
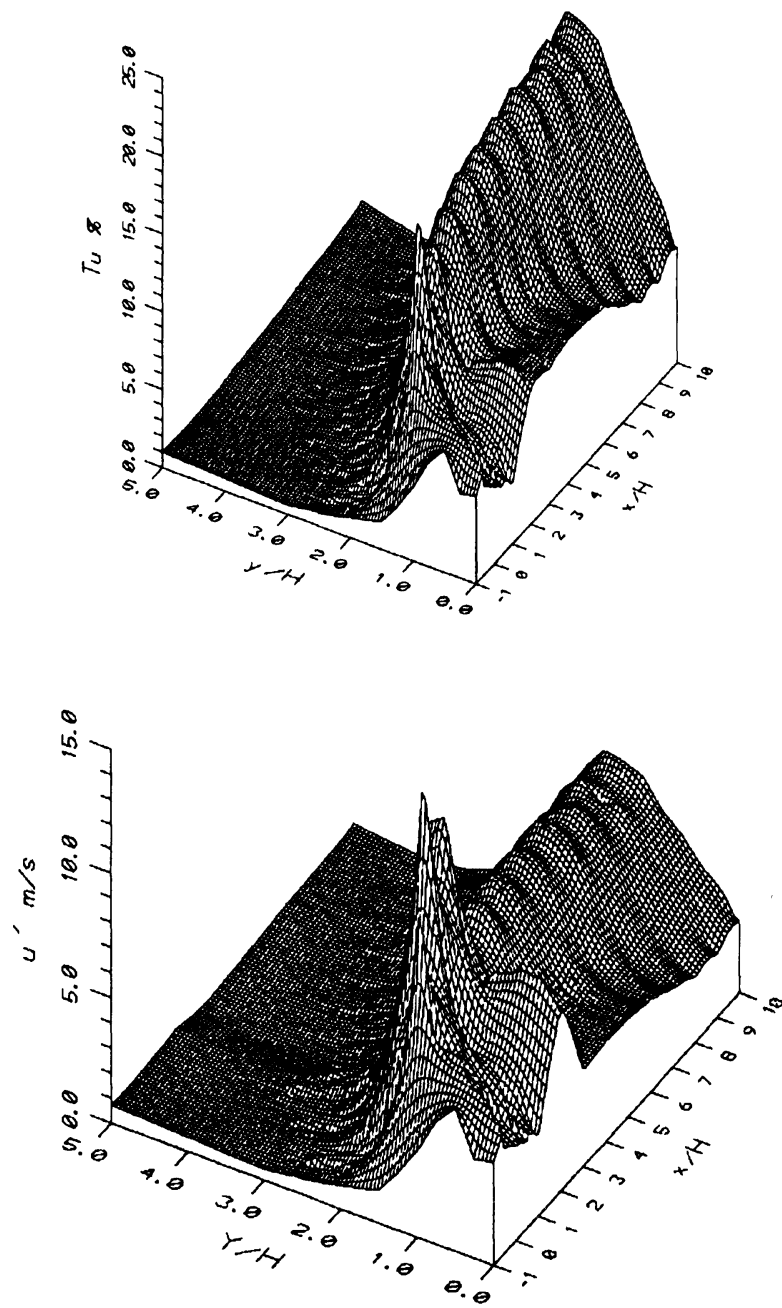

FIGURE 3 Single Rib Turbulence Intensity

The integral scale distribution around the single rib, though not displayed here, is virtually identical to that of the first rib in the in-line configuration, as shown in Figure 6. The integral scale has a value of $0.5 \mathrm{H}$ sufficiently far upstream to the rib, and rises sharply to $1 \sim$ $2 \mathrm{H}$ approximately one to two rib-heights ahead of the rib. This increase in integral scale and turbulence intensity appears to be the main cause for an unusual increase in heat transfer near the region immediately upstream to the $\mathrm{rib}$, even though it is a separation zone Chyu and $\mathrm{Wu}$, [1989]; Acharya et. al., [1993].

\section{In-Line Ribs}

The first period: Figure 4 shows the mean velocity profiles near the rib for the first period of the multiple rib geometry. The mean flow ahead of the first period rib 
reveals a developing profile as the boundary layer grows progressively from $\mathrm{x} / \mathrm{H}=-5$ to $\mathrm{x} / \mathrm{H}=-1$. As a typical well-behaved boundary layer, the near-wall Tu levels are in the $10 \%$ range. The reattachment length behind the rib, estimated by the mean velocity gradient, is around $\mathrm{X}_{\mathrm{r}} / \mathrm{H}$ $=6 \sim 7$, which is very comparable to that of the single rib case.

The turbulence intensity and integral scale distributions are shown in Figures 5 and 6. The Tu characteristics overall are quite similar to those of a single rib. The prevalence of highly turbulent shear layer is evident as the values of Tu exceed $20 \%$ and persist downstream. Because both top and bottom walls are mounted with ribs, there are a pair of peaks with a trough between them. Significantly different from the single rib case, the value of Tu near the channel core grows from the entering freestream level $(0.7 \%)$ to $\sim 12 \%$ at the next rib period. This is due mainly to the interaction of two shear layers generated by the opposing ribs. The elevated turbulence level in the mainstream is considered to be responsible for the heat transfer enhancement in a rib-roughened channel. The nature of rib arrangement in conjunction with the rib-channel geometric relationship should have a significant impact on the development of such a shear layer interaction.
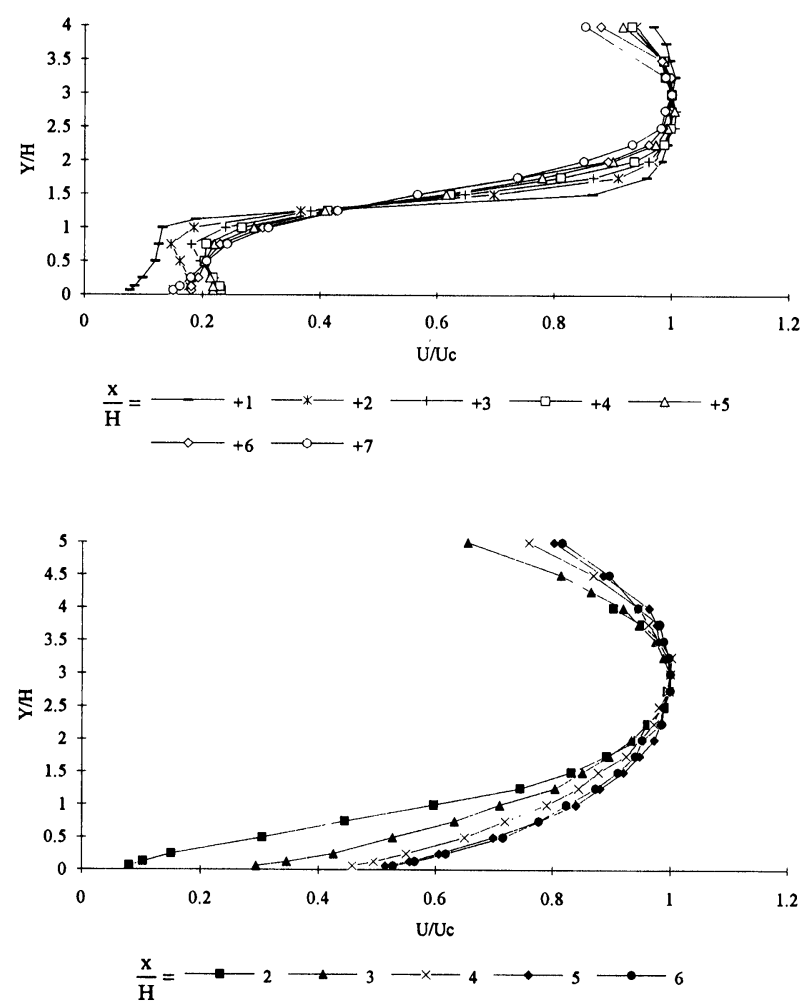

FIGURE 4 First Period, In-Line Rib Mean Velocity
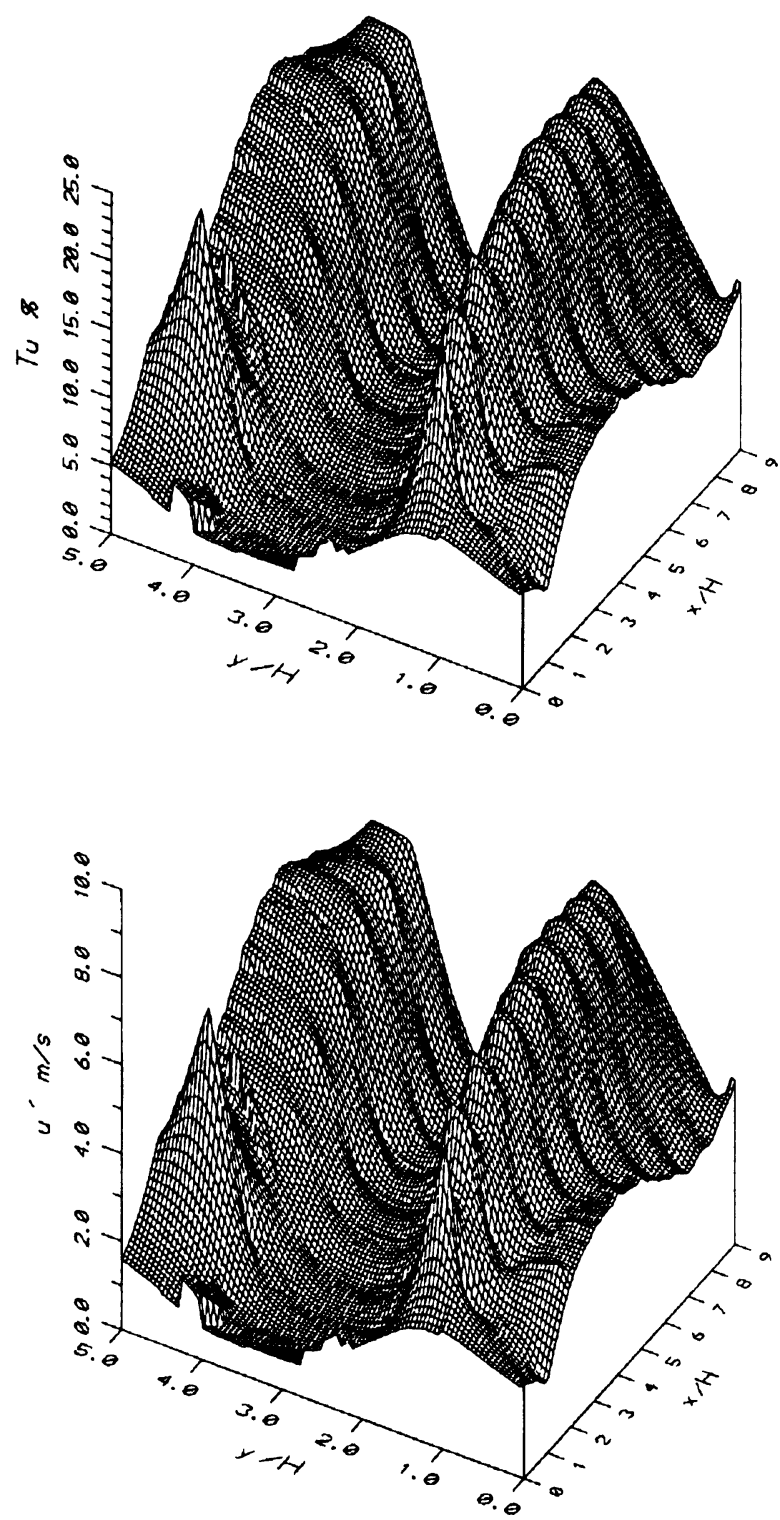

FIGURE 5 First Period, In-Line Rib Turbulence Intensity

The integral scale distribution behind the rib shows a maximum, approximately 2 to $2.5 \mathrm{H}$, near the center line of the channel. Nevertheless the integral scale in the recirculation zone $(\mathrm{y} / \mathrm{H} \leq 1)$ appears to be smaller, which is limited by the rib size. The first period appears to have the strongest variation of integral scale across the channel height, compared to the second and third periods. For the approaching flow, the integral scale displays more or less a uniform distribution, about $0.5 \mathrm{H}$, across the channel, and a sharp rise to about 1 to $2 \mathrm{H}$ immediately ahead of the rib around $\mathrm{x} / \mathrm{H}=-2$. Note that these 

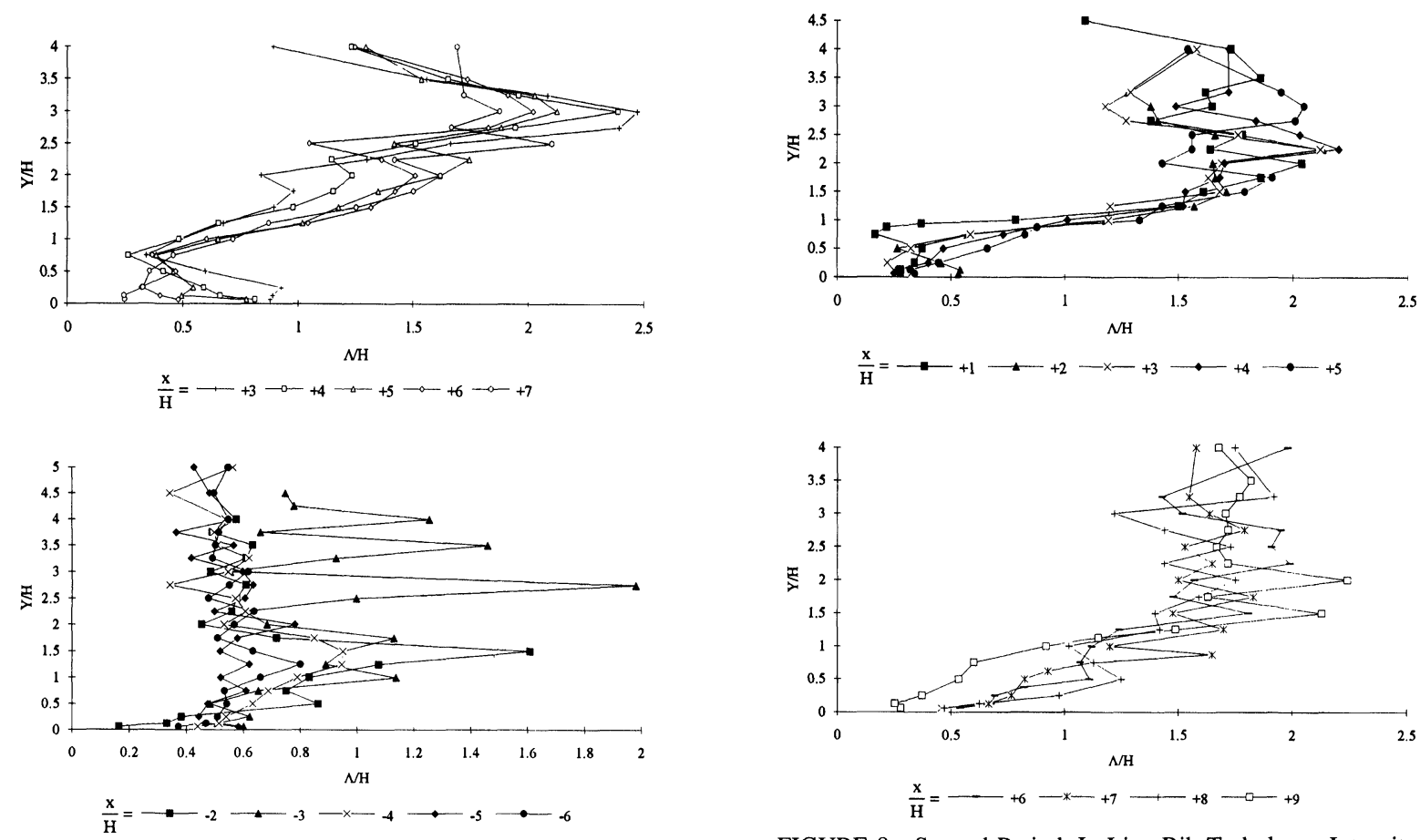

FIGURE 6 First Period, In-Line Rib Integral Length Scale

FIGURE 8 Second Period, In-Line Rib Turbulence Intensity

features discussed above are also representative of the single rib case, as mentioned earlier.
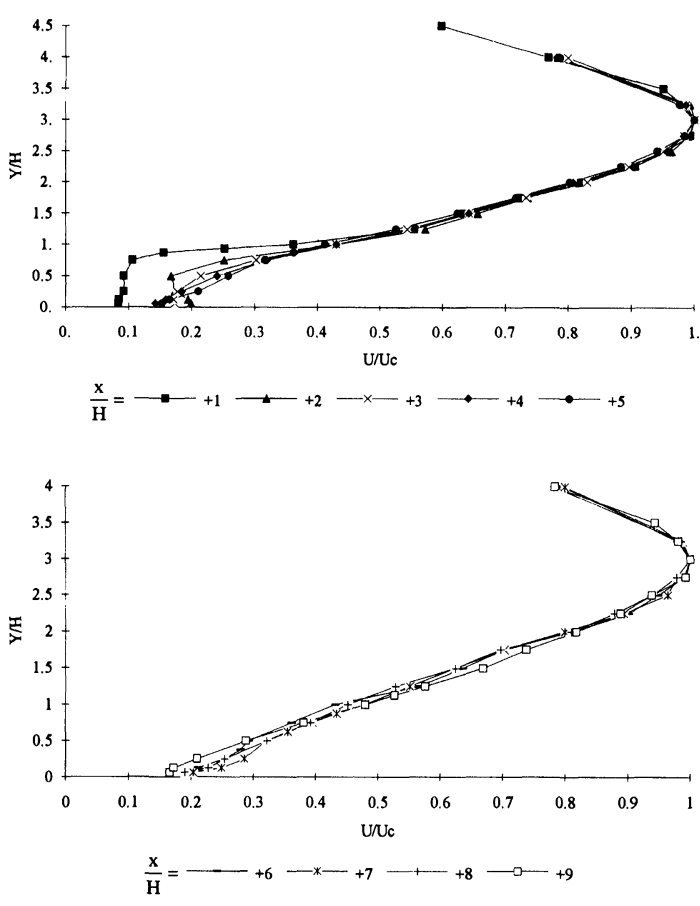

FIGURE 7 Second Period, In-Line Rib Mean Velocity

The second period: Figure 7 shows the mean velocity profile in the second period. A significant finding is that the reattachment location is relatively shorter, at $\mathrm{x} / \mathrm{H}$ $=3$ to 4 , compared to the first period. The fluctuation profile, as shown in Figure 8, approaches 20\% again for the pair of peaks signifying the dominance of the rib-induced shear layer. Between the peaks, the magnitude of $\mathrm{Tu}$ in the channel core flow starts at approximately $12 \%$ behind the rib and grow to $16 \%$ at the start of the third period. To a certain extent such elevated mainstream turbulence levels induce more effective mixing which, in turn, shortens the reattachment length. Meanwhile, the integral scale in the mainstream $(1.5<$ $\mathrm{y} / \mathrm{H}<4.5$ ) increases to a nearly constant 1.5 to $2.0 \mathrm{H}$ in the second period, as shown in Figure 9.

The third period: The mean velocity profiles of Figure 10 show the reattachment location for the third period in-line multiple ribs is located between an $\mathrm{x} / \mathrm{H}=$ 3 to 4 just as it is for period two ribs. This agrees with several earlier findings concerning either momentum or heat transfer for the developed (periodic) flow regime in rib channels. Aytekin and Berger [1979] reported a reattachment length of $3.1 \mathrm{H}$ under a fully rough condition. Using the water absorbent technique, Williams and Watts [1966] found the reattachment-induced maximum heat transfer coefficient occurs at about $3.5 \mathrm{H}$. The 
turbulence intensity, shown in Figure 11, is now remaining at about $20 \%$ with a little growth to $23 \%$ for the twin peaks. The trough between the peaks begins at $\sim 14 \%$ behind the rib and grows to $20 \%$ at the start of the fourth period. The integral scale is likewise increasing slightly compared to the second period, with the channel core approaching 2 to $3 \mathrm{H}$ in Figure 12. The profiles of Tu and integral scale are expected to have reached a nearly periodic set of values after the third period.

\section{Staggered Ribs}

Since the transport feature in the developed regime bears the most practical significance, only the third period results are presented here for comparison with their in-line counterparts. Because of asymmetric arrangement, the third period for the staggered ribs begins over the top of the third rib on the bottom wall and the mid-pitch between the second and the third ribs on the top wall, as illustrated in Figure 1. In addition, within the period, the upstream half domain is a mirror image of the downstream domain, and vice versa. According to the mean velocity profile shown in Figure 13, the reattachment location, compared to the in-line case, is shortened to between $\mathrm{x} / \mathrm{H}=2-3$. This apparently is due to an overall increase in turbulence level over the entire channel, as illustrated in Figure 14. Although the Tu
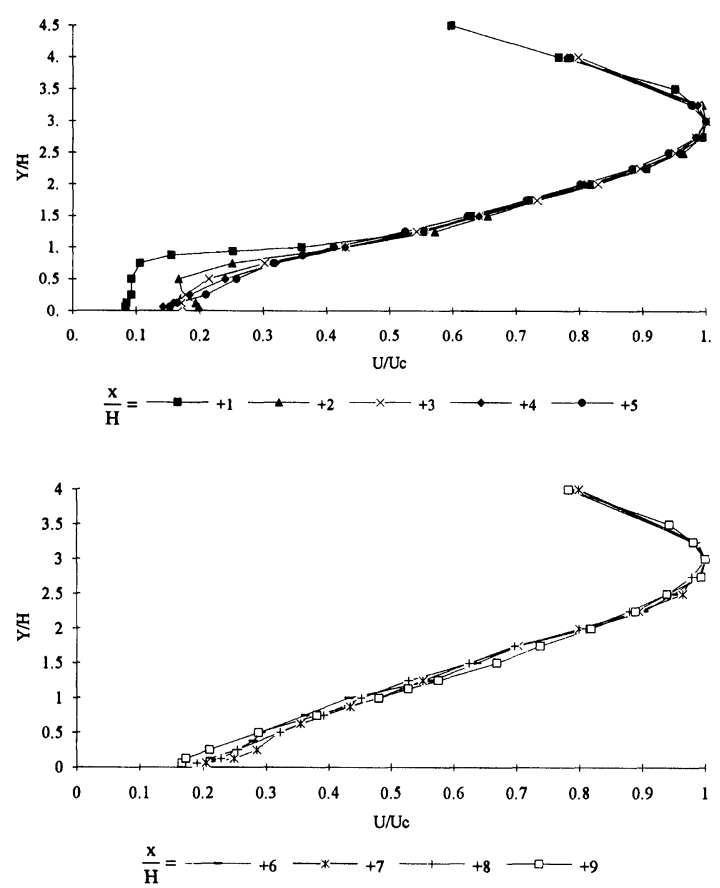

FIGURE 9 Second Period, In-Line Rib Integral Length Scale

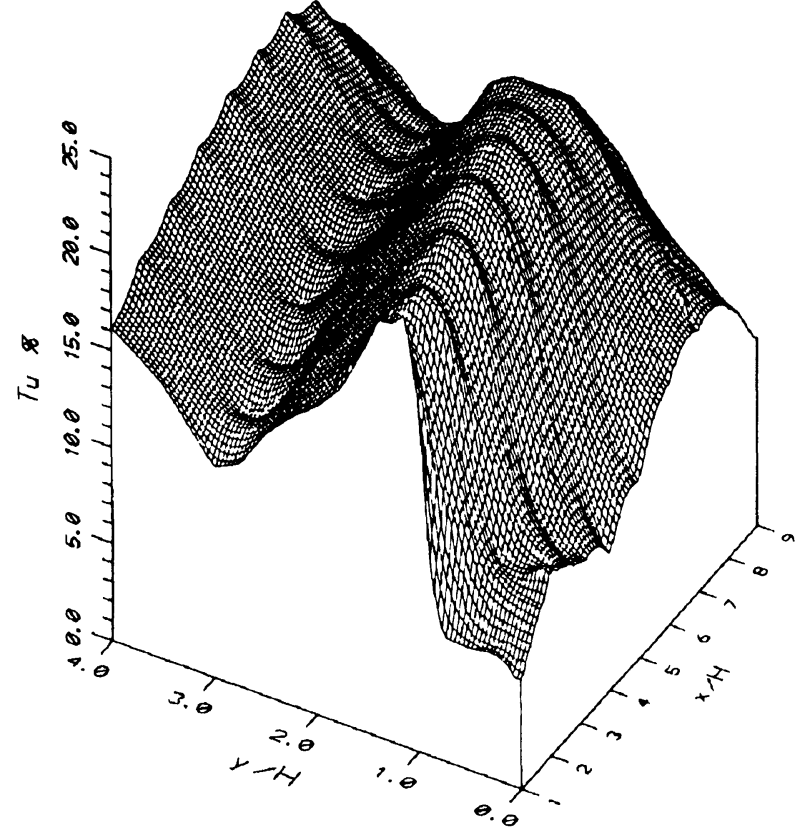

FIGURE 10 Third Period, In-Line Rib Mean Velocity

levels in the mid-channel are comparable to that of the in-line case, approximately $15-20 \%$, it increases to $30-35 \%$ in the shear layer trailing behind the rib's downstream edge. The integral scale shown in Figure 15 remains 1.5 to $2.5 \mathrm{H}$, which is about the same as that of the in-line configuration. The closer rib spacing and the

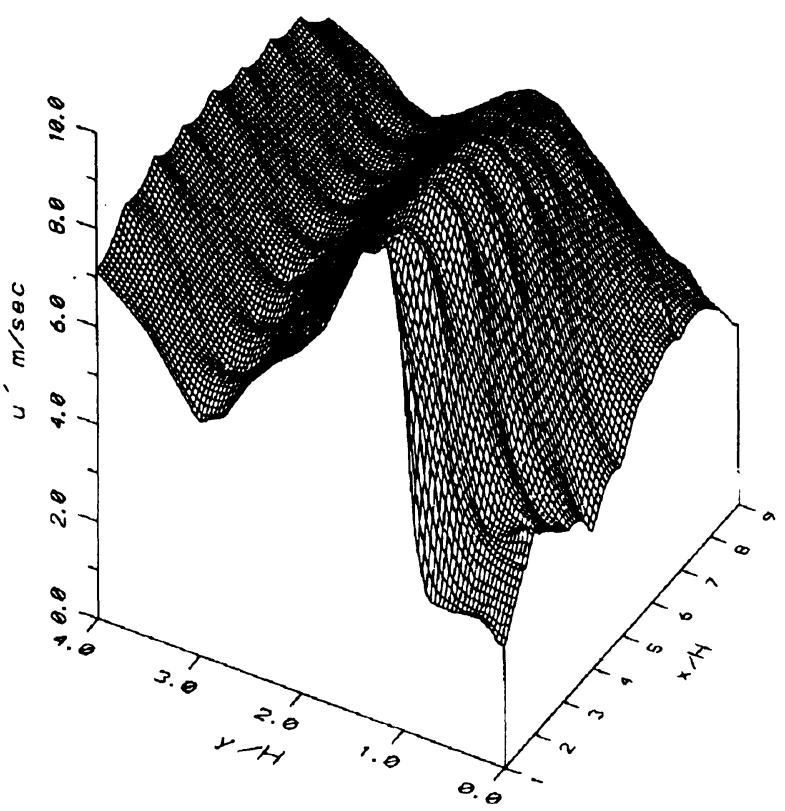

FIGURE 11 Third Period, In-Line Rib Turbulence Intensity 

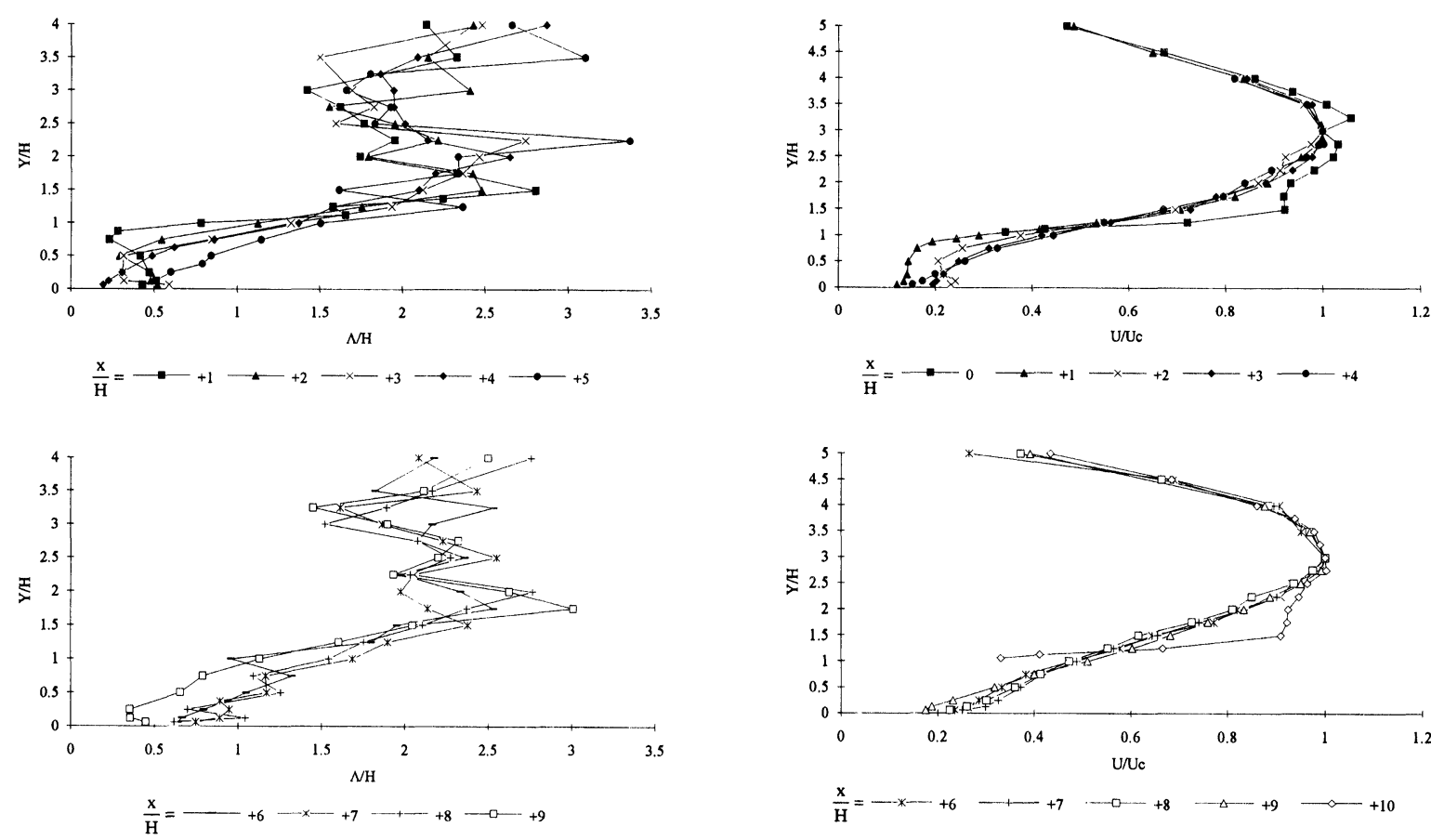

FIGURE 12 Third Period, In-Line Rib Integral Length Scale

FIGURE 13 Third Period, Staggered Rib Mean Velocity

The presence of a single rib promotes turbulence asymmetry are both more effective than the in-line configuration in increasing heat transfer.

\section{CONCLUDING REMARKS}

Hot-wire measurements have been performed to examine the mean flow and turbulence characteristics in a square channel with a single rib and multiple ribs mounted on two opposing sidewalls. Multiple ribs were arranged in both in-line and staggered configurations, with $\mathrm{p} / \mathrm{H}=10$ and $\mathrm{H} / \mathrm{D}=0.17$. Turbulence results exhibited emphasize the spatial distribution and evolution of turbulence intensity and integral scale from the flow entrance (first period) to the developed regime (third period). Significant findings summarized from the experimental data are as follows.

According to the mean flow data, the reattachment length is found to be around 6 to $7 \mathrm{H}$ behind the first rib for both in-line and staggered configurations. The same finding also exists for the single rib case. For the in-line arrangement, the reattachment length for the second and the third period is shorter, about 3 to $5 \mathrm{H}$. As a combined effect of geometric asymmetry and increase in turbulence level, the reattachment length is further shortened to $2 \sim$ $3 \mathrm{H}$ for the third period of the staggered ribs.
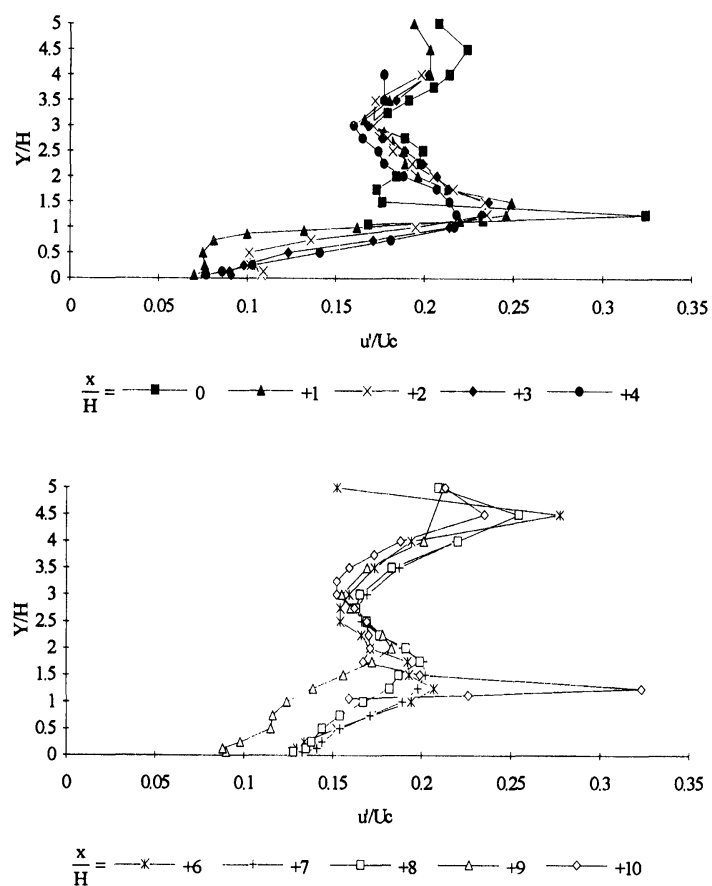

FIGURE 14 Third Period Staggered Rib Turbulence Intensity 

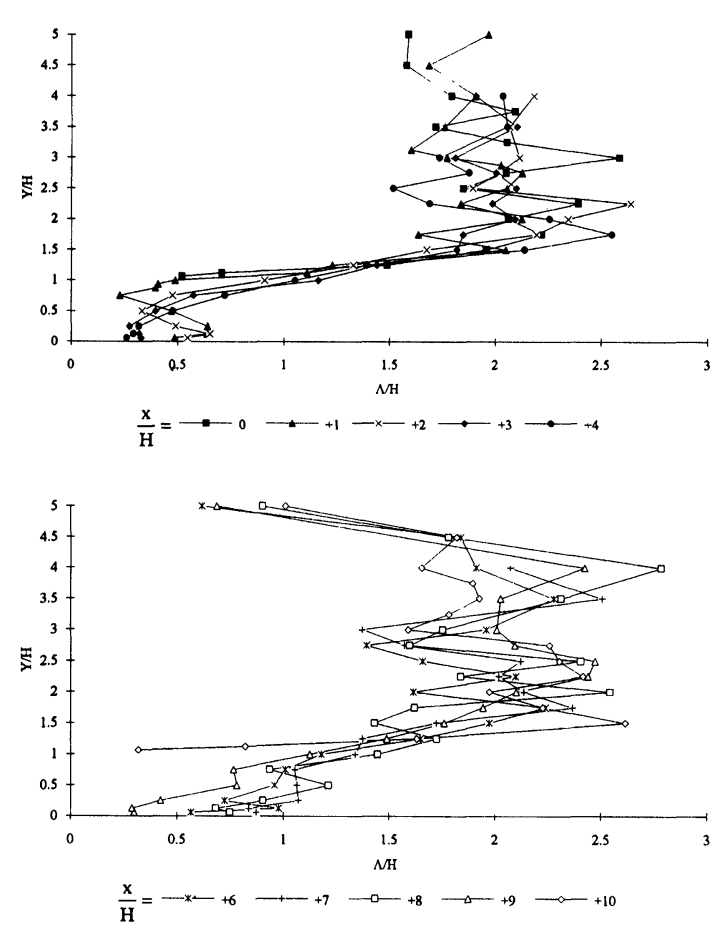

FIGURE 15 Third Period, Staggered Rib Integral Length Scale

rib. While this post-rib elevation in turbulence intensity appears to be more or less consistent for the single-rib and all the in-line cases, the staggered ribs induce a 30-35\% turbulence intensity in the separated shear layer just behind the third rib. Turbulence level in the mainstream flow increases progressively from 12 , to 16 , to $20 \%$, from the exit of the first period, to the exit of the second period, to the exit of the third period between the in-line ribs. The difference in turbulence level at the exit of the third period for staggered and in-line ribs may be responsible for the fact that staggered ribs generally have a higher heat transfer capability than the in-line ribs, particularly in the developed regime. A somewhat surprising finding is that turbulence intensity rises sharply immediately ahead of a rib. Heat transfer in the region may be significant even though this is a separation zone.

The magnitude of the integral scale of the turbulence in the channel mainstream flow $(1.5<\mathrm{y} / \mathrm{H}<4.5)$ is about $0.5 \mathrm{H}$ in the approaching flow, increases to $1.5-2.5 \mathrm{H}$ behind a single or a first-period rib, and remains more or less the same level in the downstream periods. Although local distributions may be different, the average values of integral scale for both in-line and staggered configurations are comparable. Similar to the turbulence intensity, integral scale rises sharply immediately ahead of a rib.

\section{Nomenclature}

D

$e$

$H$

$m^{\prime}$

$p$

$R e_{D}$

$T u$

$U$

$U_{B}$
$U_{c}$

$u^{\prime}$

$X_{r}$

$\Lambda$

\section{References}

Square channel height or hydraulic diameter, $\mathrm{cm}$

Rib width, $\mathrm{cm}$

Rib height or width, $\mathrm{cm}$

Channel mean mass flow, $\mathrm{kg} / \mathrm{sec}$

Rib pitch, distance between rib centerlines, $\mathrm{cm}$

Reynolds number, $\rho \mathrm{U}_{\mathrm{B}} \mathrm{D} / \mu$

Turbulence intensity, $\mathrm{u}^{\prime} / \mathrm{U}_{\mathrm{c}}$

Component of mean velocity in the $x$ direction, $\mathrm{m} / \mathrm{sec}$

Bulk mean velocity, $\mathrm{m}^{1} / \rho \mathrm{D}^{2}, \mathrm{~m} / \mathrm{sec}$

Mean velocity along the channel centerline, $\mathrm{m} / \mathrm{sec}$

rms component of velocity in the $\mathrm{x}$ direction, $\mathrm{m} / \mathrm{sec}$

Measured from the center of the rib, + down stream, - up stream, cm

Reattachment length measured from the trailing edge of the rib, $\mathrm{cm}$

Perpendicular to the ribbed surface measured from channel wall, $\mathrm{cm}$

Integral length scale in the $\mathrm{x}$ direction, $\mathrm{cm}$

Acharya, S., Myrum, T. A., and Baker, R. S., 1993a, "Turbulent Flow and Heat transfer Past a Surface Mounted Two Dimensional, Rib. Part 1: Measurements," ASME-National Heat Transfer Conference, Atlanta, GA.

Acharya, S., Dutta S., and Myrum, T. A. 1993b, "Turbulent Flow and Heat transfer Past a Surface Mounted Two Dimensional Rib. Part 2: Predictions with the Standard and the Non-Linear k-e Models," ASME-National Heat Transfer Conference, Atlanta, GA

Aytekin, A. and Berger, F. P, 1979, "Turbulent Flow in Rectangular Ducts with Low Aspect Ratios having One Rough Wall," Nuclear Energy, Vol. 18, No. 1, pp. 53-63.

Berger, F. P, Hau, K. F. and Hau, F. L., 1979, "Local Mass/Heat Transfer Distribution on Surface Roughened with Small Square Ribs," International Journal of Heat Mass Transfer, Vol. 22, pp. 1645-1656.

Chyu, M. K., and Wu, L. X., 1989, "Combined Effects of Rib Angle-of-Attack and Pitch-to-Height Ratio on Mass Transfer from a Surface with Transverse Ribs," Experimental Heat Transfer, Vol. 2, pp. 291-308.

Edward, F. J. and Sheriff, N., 1962, "The Heat Transfer and Friction Characteristics for Forced Convection Air Flow Over a Particular Type of Roughness Surface," International Developments in Heat Transfer, Proc. 1961-1962 Heat Transfer Conference, pp. 415-425.

Han, J. C., Glickman, L. R. and Rohsenow, W. M., 1979, "An Investigation of Heat Transfer and Friction for Rib-Roughened Surfaces," International Journal of Heat Mass Transfer, Vol. 21, pp. 1143-1156.

Hsieh, S. S. and Hong, Y. J., 1988, "Separating Flow Over Repeated Surface-Mounted Ribs in a Square Duct," AIAA Journal, Vol. 27, No. 6, pp. 770-776.

Klein, D. E., Miles, J. B. and Bull, S. R., 1979, "Pressure Drop Measurements and Flow Visualization Surrounding Roughness Elements," Journal of Energy, Vol. 18, No. 1, pp. 53-63.

Kottke, V., 1982, "Influence of Temperature and Concentration Boundary Layers at Separation of Heat and Mass Transfer in Separated 
Flows," Proc. 7th International. Heat Transfer Conference, Munich, Vol. 3, pp. 177-182.

Lamb, J. P. and Thompson, J. L, 1983, "Mean Flow Characteristics Downstream of a Family of Single Planar Protuberances on a Flat Plate," ASME Applied Mechanics, Bioengineering and Fluid Engineering Conference, Houston, June 20-22, 1983.

Mantle, P. L., 1966, "A New Type of Roughened Heat Transfer Surface Selected by Flow Visualization Technique," Proc. 3rd International Heat Transfer Conference, Chicago, Vol. 1, pp. 45-55.

Sato, H., Hishida, K., and Maeda M., 1992, "Characteristics of Turbulent Flow and Heat Transfer in a Rectangular Channel with Repeated Rib Roughness," Experimental Heat Transfer, Vol. 5, pp. $1-16$.
Simpson, R. L., 1981, "REVIEW-A Review of Some Phenomena in Turbulent Flow Separation," Journal of Fluid Engineering, Vol. 103, pp. 520-533.

Williams F. and Watts, J., 1970, "The Development of Rough Surfaces with Improved Heat Transfer Performance and a Study of Mechanisms Involved," Proc. 4th International Heat Transfer Conference, Versailles, Vol. 4, Paper FC 5.5.

Yokosawa, H., Fujita, H., Hirota, M. and Iwata, S., 1989, "Measurement of Turbulent Flow in a Square Duct with Roughened Walls on Two Opposite Sides," International Journal of Heat and Fluid Flow, Vol. 10, No. 2, pp. 125-130. 

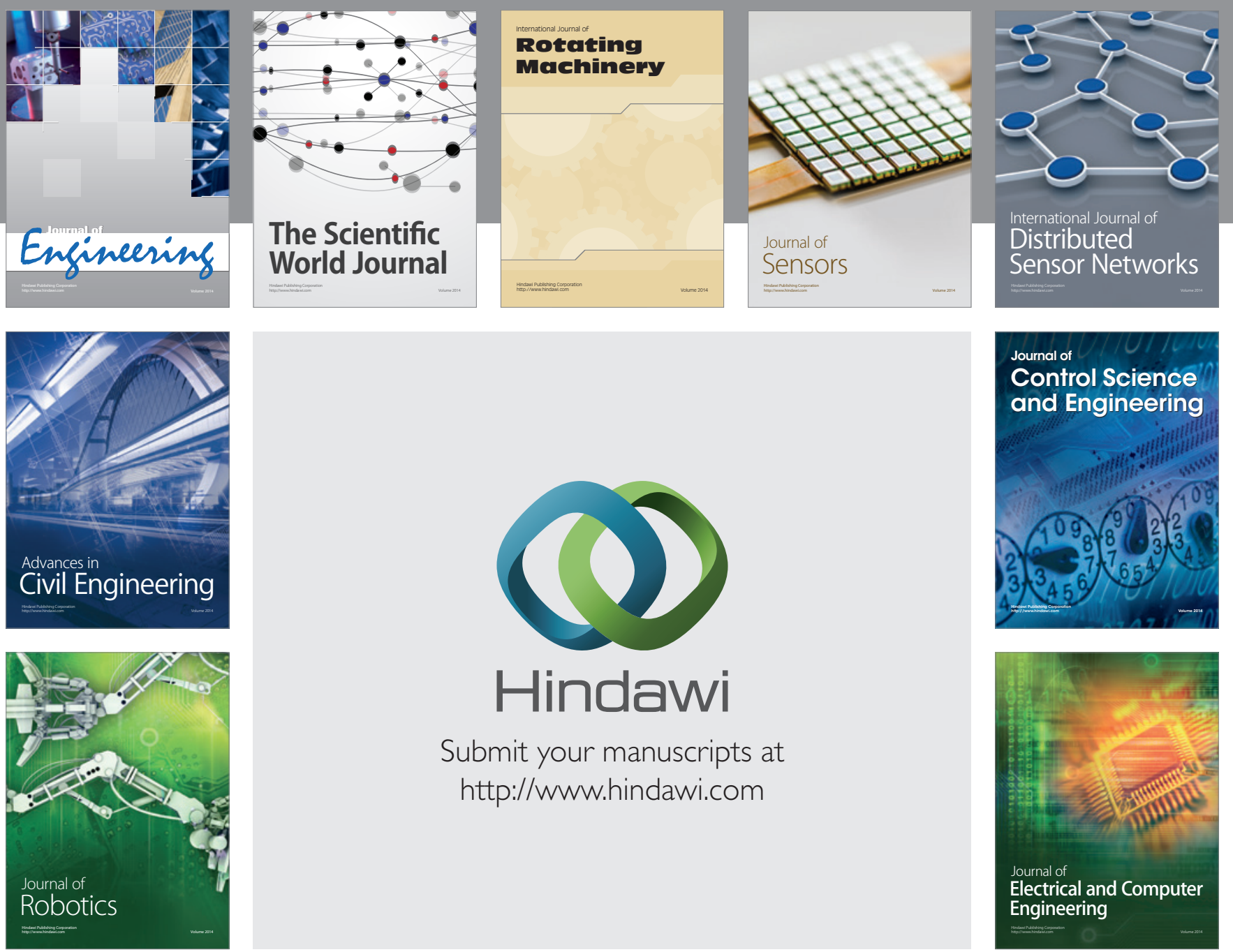

Submit your manuscripts at

http://www.hindawi.com
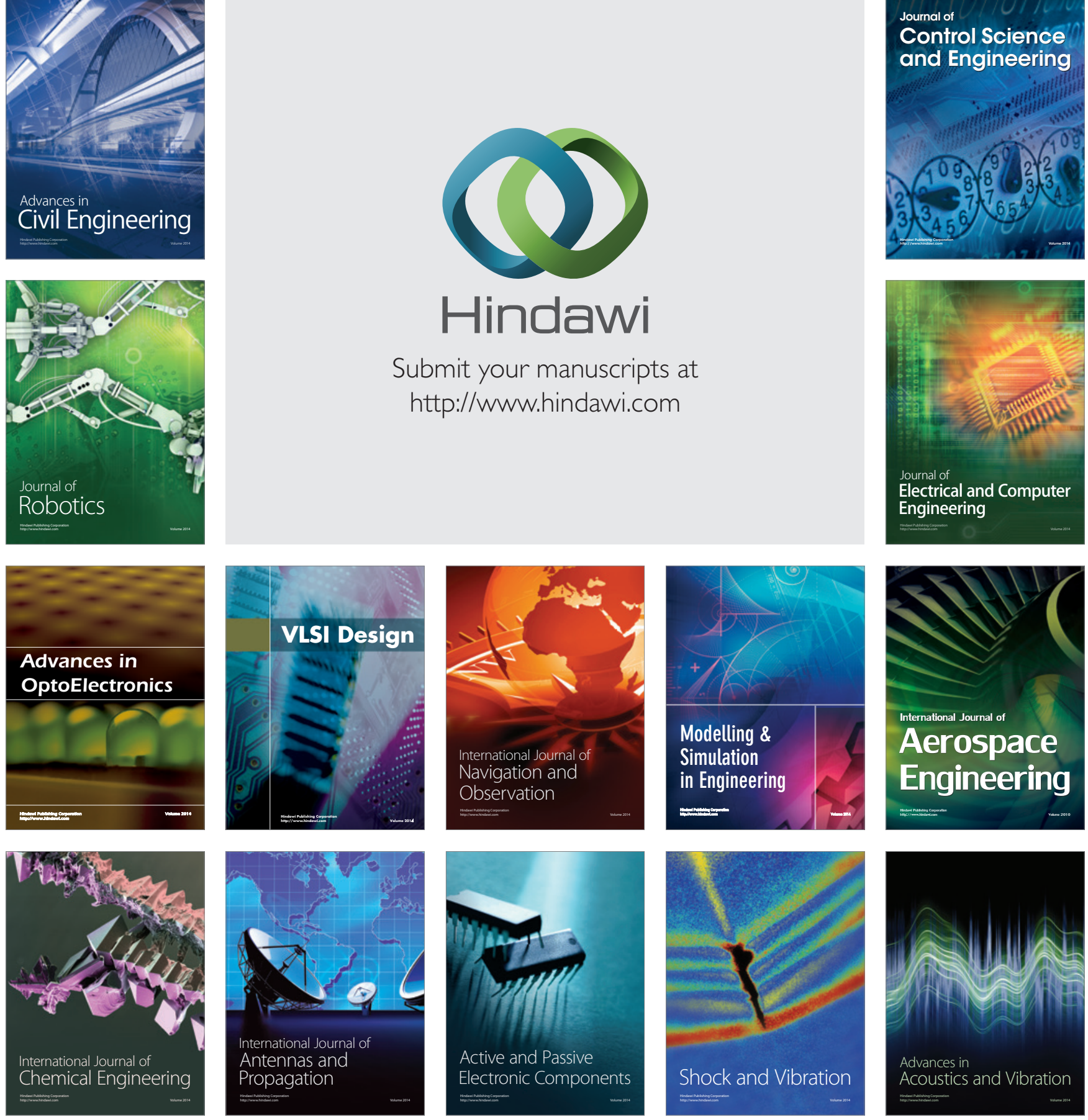